WellBeing International

WBI Studies Repository

8-29-2007

\title{
Nociception in Fish: Stimulus-Response Properties of Receptors on the head of Trout Oncorhynchus mykiss
}

\author{
Paul J. Ashley \\ University of Liverpool \\ Lynne U. Sneddon \\ University of Liverpool \\ Catherine R. McCrohan \\ University of Manchester
}

Follow this and additional works at: https://www.wellbeingintlstudiesrepository.org/acwp_vsm

Part of the Animal Studies Commons, Other Animal Sciences Commons, and the Veterinary

Physiology Commons

\section{Recommended Citation}

Ashley, P. J., Sneddon, L. U., \& McCrohan, C. R. (2007). Nociception in fish: stimulus-response properties of receptors on the head of trout Oncorhynchus mykiss. Brain research, 1166, 47-54.

This material is brought to you for free and open access by WellBeing International. It has been accepted for inclusion by an authorized administrator of the WBI Studies Repository. For more information, please contact wbisr-info@wellbeingintl.org.

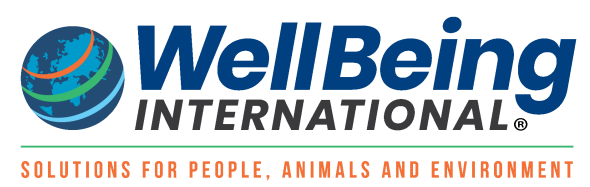




\title{
Nociception in Fish: Stimulus-Response Properties of Receptors on the head of Trout Oncorhynchus mykiss
}

\author{
Paul J. Ashley ${ }^{1}$, Lynne U. Sneddon ${ }^{1}$, Catherine R. McCrohan ${ }^{2}$ \\ ${ }^{1}$ University of Liverpool \\ ${ }^{2}$ University of Manchester
}

\section{KEYWORDS}

fish, trout, Trigeminal ganglion, nociceptor, somatosensory receptor

\begin{abstract}
This study examined stimulus-response properties of somatosensory receptors on the head of rainbow trout, Oncorhynchus mykiss, using extracellular recording from single cells in the trigeminal ganglion. Of 121 receptors recorded from 39 fish, 17 were polymodal nociceptors, 22 were mechanothermal nociceptors, 18 were mechanochemical receptors, 33 were fast adapting mechanical receptors and 31 were slowly adapting mechanical receptors. Mechanical thresholds were higher in polymodal nociceptors than in either slowly adapting or fast adapting mechanical receptors, whereas thermal thresholds of mechanothermal nociceptors were higher than those of polymodal nociceptors. Polymodal nociceptors and mechanochemical receptors gave similar responses to topical applications of acid. All receptor types except mechanothermal nociceptors showed an increase in peak firing frequency with increased strength of mechanical stimulation, with evidence of response saturation at higher intensities. Mechanothermal, but not polymodal, nociceptors showed an increase in firing response to increased temperature. None out of 120 receptors tested gave any response to the temperature range $+4^{\circ} \mathrm{C}$ to $-7^{\circ} \mathrm{C}$, indicating an absence of cold nociceptors. Attempts to evoke sensitization of receptors using chemical or heat stimuli were unsuccessful, with receptors showing either a return to control responses or irreversible damage. Comparisons are made between somatosensory receptors characterized here in a fish and those of higher vertebrates.
\end{abstract}

\section{Introduction}

Recent research reported the presence of different types of trigeminal receptor neurons, including nociceptors, for the first time in a lower vertebrate, the rainbow trout (Sneddon, 2003b; Sneddon et al., 2003a). Extensive studies on nociception in higher vertebrates have determined the characteristics of 
functionally distinct classes of nociceptor (Lynn, 1994), their stimulus-response relationships (Garell et al., 1996; Simone and Kajander, 1997; Cain et al., 2001), and the occurrence of altered sensitivity (sensitization; e.g. Andrew and Greenspan, 1999). However, detailed information on the classes and stimulus-response properties of fish nociceptors is currently lacking. Sneddon (2003b) classified somatosensory receptors on the head of the trout, based on their responses to touch, pressure, heat and chemical stimulation. These included polymodal and mechanothermal nociceptors with properties similar to those found in mammals (Sneddon, 2003b; Sneddon et al., 2003a). However, in contrast to mammals, the majority of polymodal nociceptors were A-delta fibres, based on their conduction velocities (Sneddon, 2003b); indeed a microscopy study showed that very few C-fibres are present in the trigeminal nerve of trout (c. 4\%; Sneddon, 2002). It was suggested that differences between the nociceptive systems of fish and higher vertebrates may have evolved as an adaptation to the increased risk of injury arising from the encountered in the terrestrial environment. C-fibres in mammals have a particular role in responding to prolonged noxious stimuli and a higher proportion of $\mathrm{C}$-fibres would give greater capacity for responding to chronic pain (Sneddon et al., 2003a). Whether other differences exist between fish and higher vertebrate nociceptors, for example with respect to stimulus-response properties, is unknown.

Fish show prolonged behavioural changes following noxious stimuli (Sneddon, 2003a; Sneddon et al., 2003b), raising the possibility that their nociceptors may exhibit sensitization, potentially leading to hyperalgesia, following intense stimulation or tissue damage, as do mammalian and avian nociceptors (Koltzenburg, 1999; Gentle et al., 2003). Sensitization is a process whereby the peripheral inflammatory response to noxious stimulation is accompanied by an increase in the excitability of nociceptors. Such changes in nociceptor response properties are one of the hallmarks of pain in humans (Scholz and Woolf, 2002), but it is not known whether fish nociceptors exhibit a similar response to damage. Finally, cold nociceptors, which respond to very cold, tissue damaging temperatures, have been described for birds and mammals (e.g. Necker, 2000; Simone and Kajander, 1997), but their presence in fish has not been investigated.

The present study had three aims: to characterise in detail stimulus-response properties of receptors on the head and face of trout; to determine whether these receptors show sensitization; and to investigate the presence of cold nociceptors.

\section{Results}

A total of 121 receptors were characterized from 39 fish. According to their response profiles to the different stimulus modalities, 17 were classed as polymodal nociceptors, 22 as mechanothermal nociceptors, 18 as mechanochemical receptors, 33 as fast adapting mechanical receptors and 31 as slowly adapting mechanical receptors. Polymodal and mechanothermal nociceptors (Figs. 1A, B) showed slowly adapting responses to thermal (heat) and mechanical stimuli, and polymodal receptors also responded to a chemical (acid) stimulus; neither showed any response to cold stimulation (Figs 1A, B). Mechanochemical receptors gave slowly adapting responses to mechanical and chemical stimuli (Fig. 1C). Fast and slowly adapting mechanical receptors showed clear differences in the degree of adaptation to a mechanical stimulus; fast mechanical receptors fired for less than $0.5 \mathrm{~s}$ at the onset of a maintained stimulus (Fig. 1D), whereas slow mechanical receptors continued firing for as long as the stimulus was applied (Fig. 1E). Of 120 receptors tested, none showed any response to the temperature range $+4^{\circ} \mathrm{C}$ to $-7^{\circ} \mathrm{C}$. Table 1 summarises the receptive field sizes and response thresholds of the different receptor types. Polymodal nociceptors had significantly higher mechanical thresholds than both slowly adapting and fast adapting mechanical receptors $(p<0.05)$. The thermal (heat) threshold of mechanothermal receptors was significantly higher than that of polymodal nociceptors $(p<0.05$; Table 1$)$. 
Fig. 1 - Responses of trigeminal receptors on the head of rainbow trout Oncorhynchus mykiss. Recordings show responses to heat, cold, chemical (1\% acetic acid applied topically) and mechanical stimuli. For each recording, upper trace indicates stimulus applied to the skin, middle plots instantaneous firing frequency (IFF, calculated from intervals between successive action potentials), and bottom shows extracellular, single unit recording from the trigeminal ganglion. (A) Polymodal nociceptor showing slowly adapting responses to heat, chemical and mechanical stimulation but not to cold stimulation. (B) Mechanothermal nociceptor, with slowly adapting responses to heat and force and no response to cold or acid. (C) Mechanochemical receptor with slowly adapting responses to acid and force. (D) Fast adapting mechanical receptor showing brief action potential burst at the onset of applied force. (E) Slowly adapting mechanical receptor showing prolonged response during application of force.

A

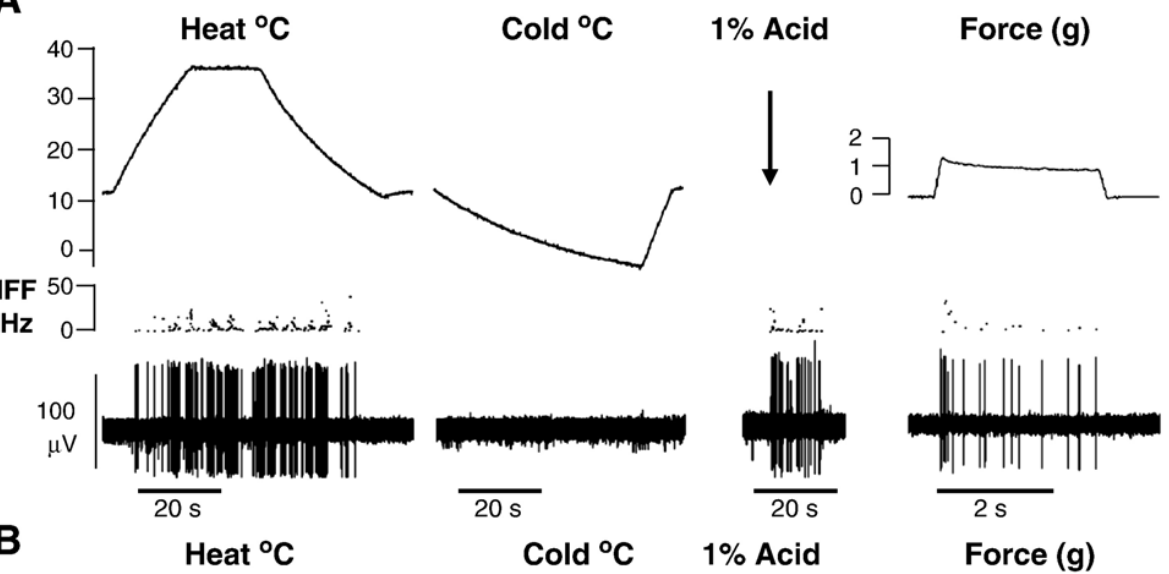

B

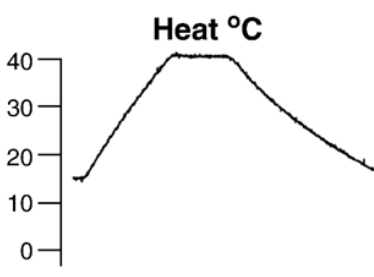

Cold ${ }^{\circ} \mathrm{C} \quad 1 \%$ Acid

Force (g)

$z^{50} 0$

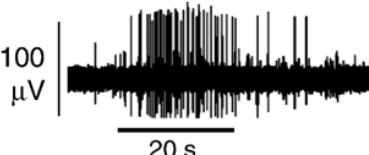

C

$1 \%$ Acid<smiles>C[12CH2]</smiles>

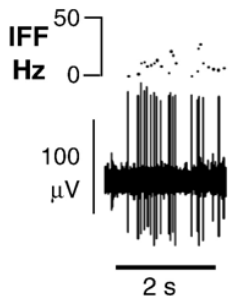

Force (g)
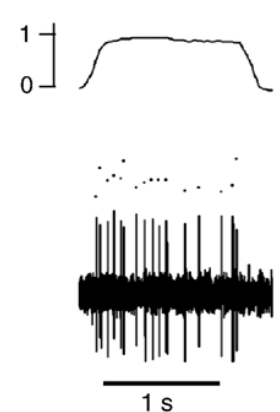

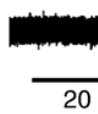

$20 \mathrm{~s}$

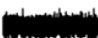

$2 s$

Force (g)

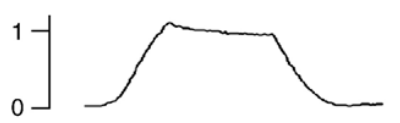

$50] \quad \therefore$

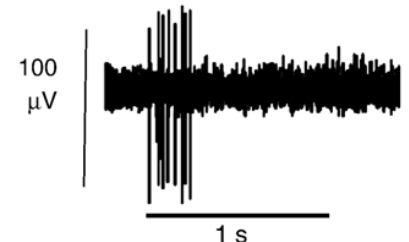

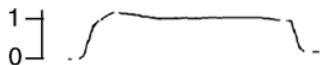

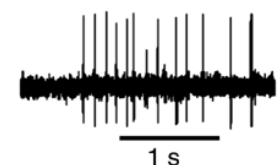

E Force (g)
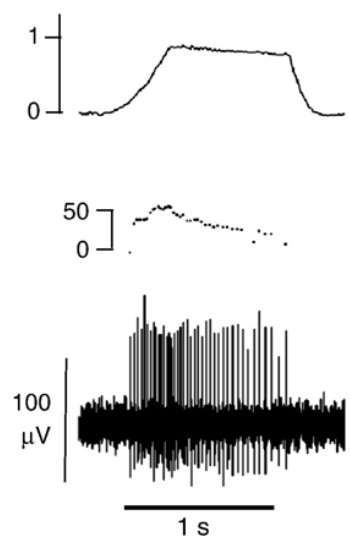
Table 1 - Properties of receptors on the head and face of rainbowtrout, recorded extracellularly from the trigeminal ganglion

\begin{tabular}{|c|c|c|c|c|c|}
\hline & Polymodal & Mechanothermal & Mechanochemical & $\begin{array}{l}\text { Fast adapting } \\
\text { mechanical }\end{array}$ & $\begin{array}{l}\text { Slowly adapting } \\
\text { mechanical }\end{array}$ \\
\hline $\begin{array}{l}\text { Receptive field } \\
\text { diameter (mm) }\end{array}$ & $2.55 \pm 0.44 n=17$ & $2.20 \pm 0.37 n=22$ & $2.63 \pm 0.39 n=18$ & $2.59 \pm 0.29 n=30$ & $2.25 \pm 0.27 n=26$ \\
\hline $\begin{array}{l}\text { Mechanical } \\
\text { threshold (g) }\end{array}$ & $1.02 \pm 0.24 n=13$ & $0.80 \pm 0.27 n=14$ & $0.71 \pm 0.21 n=18$ & $0.37 \pm 0.10 n=33$ & $0.32 \pm 0.14 n=31$ \\
\hline $\begin{array}{l}\text { Temperature } \\
\text { threshold }\left({ }^{\circ} \mathrm{C}\right)\end{array}$ & $\begin{array}{c}28.87 \pm 1.32 \\
(20.1-37.0) n=17\end{array}$ & $\begin{array}{c}33.16 \pm 0.97 \\
(22.0-40.0) n=22\end{array}$ & & & \\
\hline $\begin{array}{l}\text { Response to } \\
\text { chemical } \\
\text { stimulation }\end{array}$ & YES & NO & YES & NO & NO \\
\hline
\end{tabular}

Owing to the compliance of the skin around the head and face of the fish, it was not possible to maintain a consistent mechanical stimulus over time; the actual force exerted could not always be kept constant. For this reason, we recorded only the peak firing frequency in response to mechanical stimuli, since a measure of the number of spikes over a specific time period would yield misleading results. Most receptors increased their peak firing rate in response to an increase in force of mechanical stimulation (Figs. 2A, B). A two-factor ANOVA investigating the response of all receptor types to above threshold mechanical stimuli showed no effect of receptor type or factor interaction, but there was an effect of stimulus strength $(p<0.0005)$. Fast adapting mechanical receptors showed a marked increase in peak firing frequency when response to threshold $+150 \%$ was compared to threshold $+50 \%(p<0.05$; Fig. $2 B)$. Mechanochemical receptors also showed this increase $(p<0.05)$ as well as a significant increase when threshold $+100 \%$ was compared to threshold $+50 \%(p<0.05)$. Polymodal nociceptors increased their firing rate when threshold $+100 \%$ was compared to threshold $+50 \%(p<0.05)$. Slowly adapting mechanical receptors displayed a similar increase in response between threshold $+50 \%$ and threshold $+100 \%$, which approached significance $(p=0.052)$. None of the receptor types showed significant differences between responses to threshold $+100 \%$ and threshold $+150 \%$ stimuli. Only slowly adapting mechanical receptors showed a significant correlation between mechanical stimulus strength and peak firing frequency $(p<0.05)$. Fig. $2 \mathrm{C}$ plots the distribution of mechanical thresholds for the different receptor types. Most types showed thresholds over the full range of stimulus intensities. However, there was some evidence for two subgroups within both the mechanothermal and mechanochemical types, based on their mechanical thresholds (respectively: thresholds of $0.002-0.1 \mathrm{~g}$ and $1.0-2.5 \mathrm{~g}$; and of $0.002-0.5 \mathrm{~g}$ and 1.0-2.6 g). Notably, a marked proportion of all receptors had low thresholds-less than $0.2 \mathrm{~g}$, though this was less the case for polymodal receptors. Linear regression analysis revealed a significant $(p<0.04)$ negative correlation between mechanical threshold and the peak firing frequency response to a threshold $+50 \%$ mechanical stimulus; units with lower threshold showed a greater firing response. However there was no correlation between mechanical threshold and the ability to encode suprathreshold stimuli, nor between mechanical and thermal thresholds of individual polymodal and mechanothermal receptors.

In response to heat stimulation, mechanothermal receptors showed a significant increase in both peak firing frequency $(p<0.05)$ and the number of action potentials in the first $10 \mathrm{~s}$ of the response $(p<0.05)$ when response to threshold $+8^{\circ} \mathrm{C}$ was compared to threshold temperature (Fig. 3A). In contrast, polymodal receptors did not show a significantly greater response to the higher compared to the lower 
temperature (Fig. 3A). Responses of polymodal nociceptors and mechanochemical receptors to acid application were similar (cf. Figs. 1A, C); there was no difference in peak firing frequency or number of spikes in $5 \mathrm{~s}$ between the two receptor types (Fig. 3B). Only one concentration of acid (1\%) was used in this study; topical application of $2 \%$ acetic acid caused irreversible damage to nociceptors, while $0.1 \%$ and $0.5 \%$ produced no response.

A range of approaches was used in an attempt to demonstrate receptor sensitization. Injection with formalin adjacent to the receptive field $(0.1 \%, n=4 ; 1 \%, n=4)$ resulted in a permanent loss of receptor function and no spontaneous activity in all but one of the receptors treated in this way. Upon reassessment of thermal threshold in this receptor, 9 min post-injection, the threshold and receptive field size were unchanged. However the firing response was greatly increased (Fig. 4). This did not appear to be due to changes in stimulus receptor coupling produced by oedema. This receptor then ceased firing when the thermode temperature was returned to $15^{\circ} \mathrm{C}$ and did not respond to further stimulation. Neither the use of heat $\left(>45^{\circ} \mathrm{C}, n=4\right)$ nor a noxious cold stimulus $\left(\leq 8^{\circ} \mathrm{C}, n=5\right)$ was successful in inducing receptor sensitization; instead these stimuli resulted in permanent loss of receptor activity. Reducing the strength of the temperature stimulus (i.e. heating to $42^{\circ} \mathrm{C}$ or cooling to $-7^{\circ} \mathrm{C}$ ) was successful in maintaining polymodal receptor function but no changes in heat or mechanical threshold, firing response to threshold or suprathreshold stimuli, or in receptive field size occurred. Topical application of $1 \%$ acetic acid did not alter receptor heat or mechanical thresholds $(n=6)$ whereas subcutaneous injection of $1 \%$ acetic acid led to a permanent loss of receptor activity $(n=6)$. Subcutaneous injection of $0.01 \%(n=3)$, $0.1 \%(n=4)$ or $0.5 \%$ acetic acid $(n=6)$ led to a period (ca. $60 \mathrm{~s}$ ) during which the receptor was unresponsive, followed by a return of normal function.

\section{Discussion}

The trigeminal receptor neuron types described here for rainbow trout correspond to those previously identified by Sneddon (2003b), who defined two of them (polymodal and mechanothermal) as nociceptors. Mechanical thresholds covered a large range, up to a maximum of $5 \mathrm{~g}$. This range is closer to, though still lower than, that reported for low threshold $(A \beta)$ cutaneous mechanoreceptors (0.04-6 g), as opposed to $A \delta$ (c. 0.01-11 g) and C-fibre (c. 0.1-18 g) nociceptors, in mouse glabrous skin (Cain et al., 2001). Gentle (1989) reported thresholds of 0.1 to $2 \mathrm{~g}$ for low threshold mechanoreceptors and 5 to $50 \mathrm{~g}$ for high threshold cutaneous nociceptors on the beak of chickens. Thus, trout cutaneous receptors recorded here are more sensitive overall to mechanical stimuli than those of mammals and birds, with some responding to stimuli as low $0.001 \mathrm{~g}$. Mechanical thresholds for all receptor classes were in the same range. However, both mechanothermal and mechanochemical receptors showed some evidence of falling into two subgroups, with respect to mechanical threshold. Interestingly, those receptors with low thresholds generated significantly greater firing responses to suprathreshold stimuli, again emphasising the extreme sensitivity of some cutaneous receptors recorded in this study. It is likely that fish, continuously exposed to external water pressure and to bacterial and fungal agents, require greater cutaneous sensitivity, including for nociception, than terrestrial animals. This might in turn be linked to the active role of fish skin in immune responses to infection (Gonzalez et al., 2007). In our experiments, the face of the fish was out of water during recording, though we kept it damp by applying water periodically. This raises the possibility that, under normal conditions, low threshold mechanical receptors are tonically active due to water movements, allowing them to code for both positive and negative changes in water pressure on the skin as the fish swims. 
Fig. 2 - Mechanical response thresholds and stimulus-response properties of trigeminal receptors. (A) Example of a mechanochemical receptor on the head of trout, responding with increased firing frequency (middle trace) to increasing intensity of mechanical stimulation (upper trace). Bottom trace shows single unit action potential recording from trigeminal ganglion. (B) Peak firing frequency (mean \pm s.e.m., $n$ indicated below) generated by different receptor types in response to three intensities of mechanical stimuli: threshold $+50,100$ and $150 \%$. * indicates significant $(p<0.05)$ difference compared to threshold $+50 \%$ in the same receptor type. Pearson correlation analysis revealed a significant correlation $(p<0.05)$ between mechanical stimulus strength and peak firing frequency for slowly adapting mechanoreceptors only. (C) Distribution plot of mechanical threshold of different receptor types, showing evidence of subgroupings for mechanothermal and mechanochemical receptors.
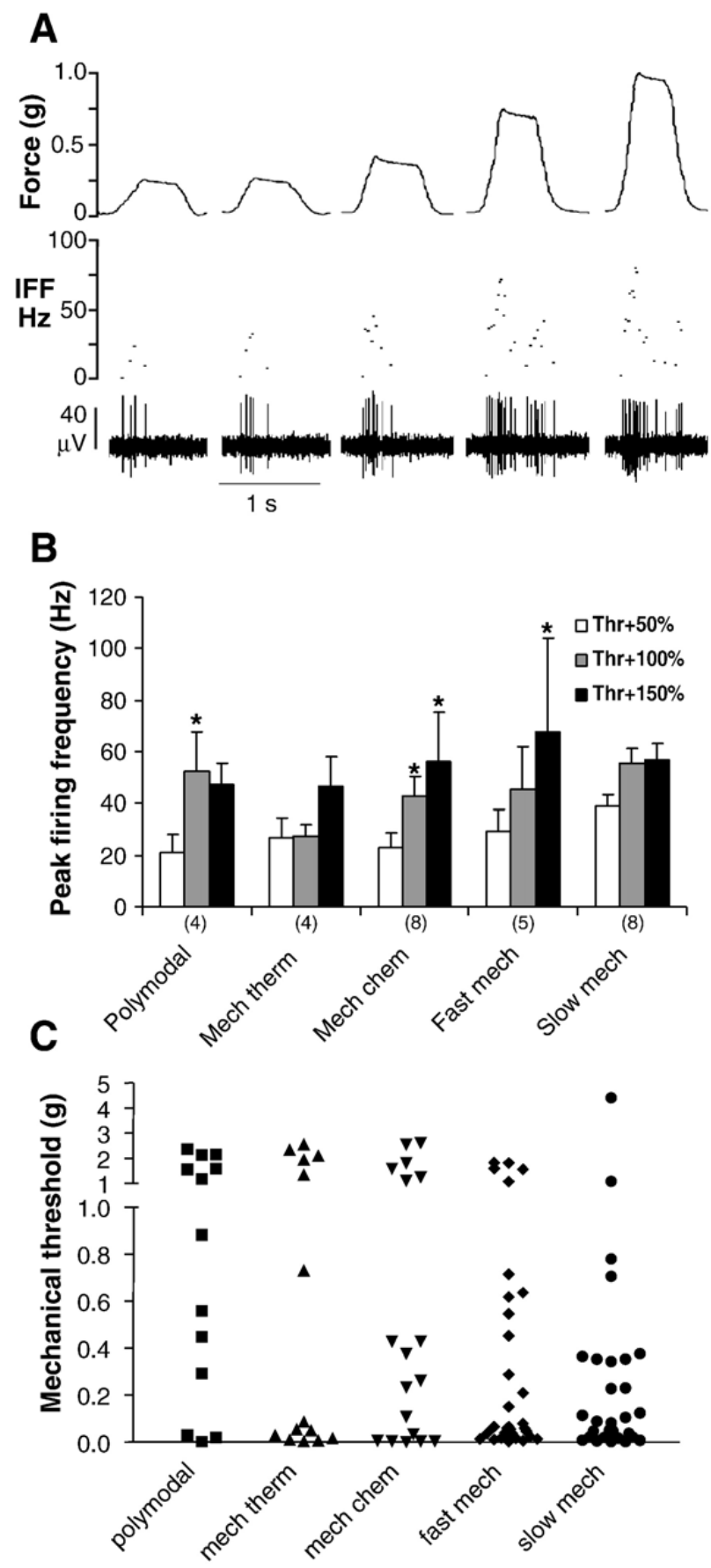
Fig. 3 - Responses of polymodal, mechanothermal and mechanochemical receptors to heat and chemical stimuli. (A) Peak firing frequency and number of spikes in first $10 \mathrm{~s}$ of the response (mean \pm s.e.m., $n$ indicated below) of polymodal and mechanothermal receptors to threshold and threshold $+8^{\circ} \mathrm{C}$ ramp and hold heat stimulation. Mechanothermal but not polymodal receptors show greater firing frequency and spike number with increased temperature. * indicates a significant difference between different temperatures $(p<0.05)$. (B) Peak firing frequency and number of spikes in first $5 \mathrm{~s}$ of the response (mean \pm s.e.m., $n$ indicated below), in polymodal and mechanochemical receptors, following application of single drop of $1 \%$ acetic acid onto the skin at the centre of the receptive field. There was no difference in either response parameter between the two receptor types.
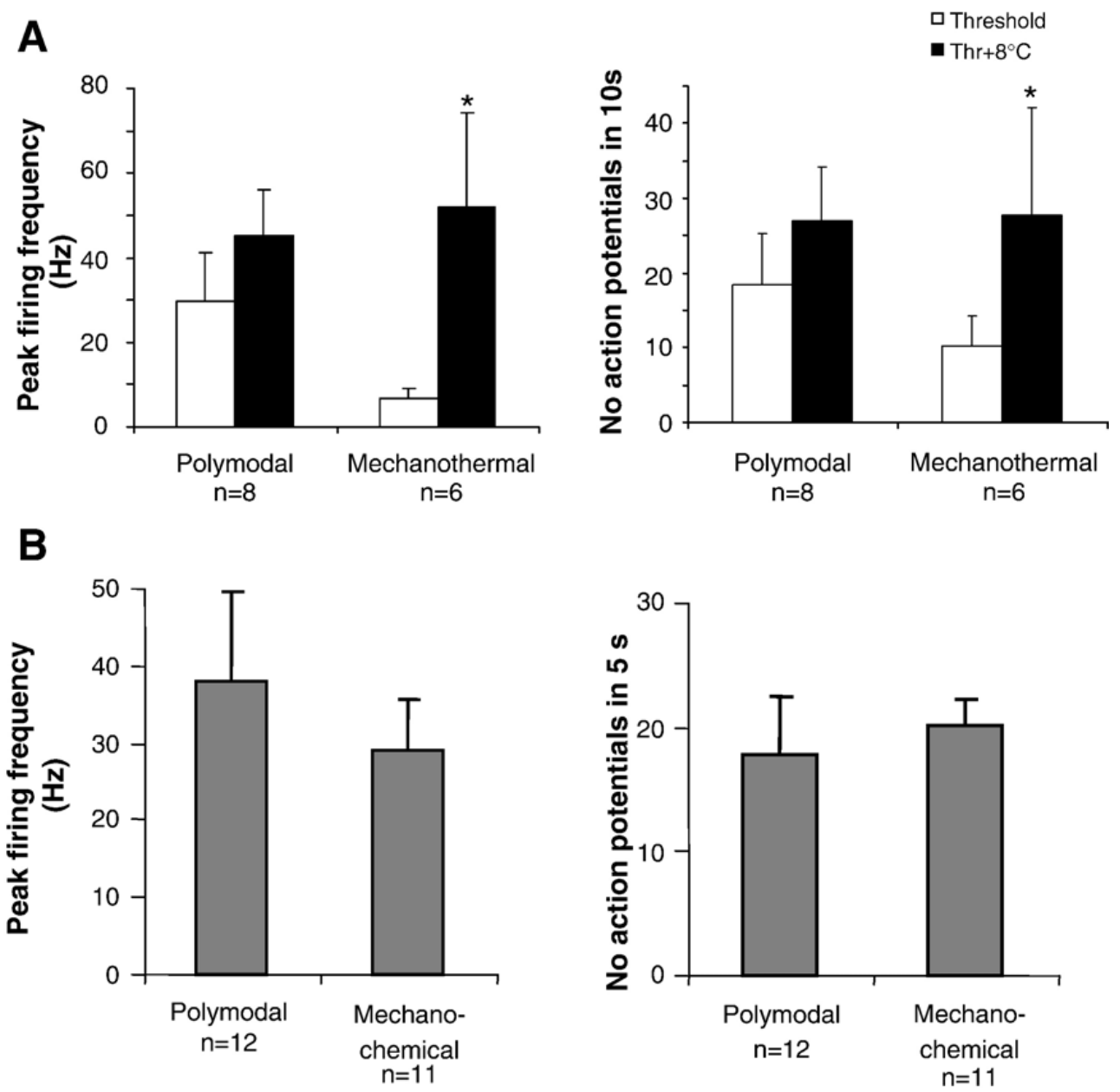

All receptor types except for the mechanothermal nociceptors showed an increase in firing frequency with increased strength of mechanical stimulation. They all showed some level of response saturation, with response at threshold $+150 \%$ being no different from that recorded at threshold $+100 \%$. Mechanical stimulus response profiles show considerable variation in both mammalian and avian nociceptors (Lynn, 1994;Garell et al., 1996; Gentle et al., 2001). For example, in feline hairy skin, nociceptors with low mechanical thresholds show response saturation whereas those with high thresholds do not (Garell et al., 1996). In our study, however, there was no correlation between mechanical threshold and the ability to encode stimulus intensity. Overall, polymodal nociceptors had significantly higher mechanical thresholds than fast and slowly adapting mechanical receptors, indicating that the former do indeed code for noxious mechanical stimuli. Similar distinctions have been made between mechanoreceptors and polymodal nociceptors in mammals (Leem et al., 1993; Lynn, 1994). Mechanothermal nociceptors had higher heat thresholds than polymodal nociceptors suggesting that the former may be specialised to detect high 
temperatures in the noxious range. The responses of these two receptor types to increased heat stimuli indicate that mechanothermal receptors provide information on intensity, whereas polymodal receptors convey only qualitative information (i.e. on and off). Conversely, their responses to suprathreshold mechanical stimulation suggest that the polymodal nociceptors provide intensity coding for mechanical stimuli, whereas mechanothermal nociceptors do not.

Fig. 4 - Sensitization of a mechanothermal receptor to heat following noxious chemical stimulation. The firing response to ramp and hold heat stimulation is shown (A) before and (B) 9 min after subcutaneous injection of $1 \%$ formalin $<1 \mathrm{~mm}$ from the receptive field. Upper trace shows heat stimulus, middle trace plots instantaneous firing frequency (IFF) and lower trace shows extracellular single unit recording from the trigeminal ganglion. Thermal threshold remains the same but firing frequency is greatly increased following formalin injection. This unit subsequently became non-responsive.

A

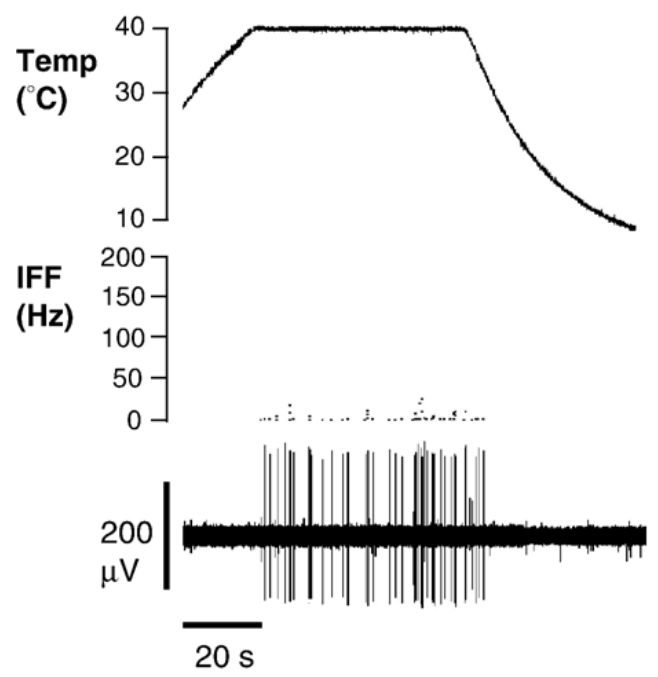

B
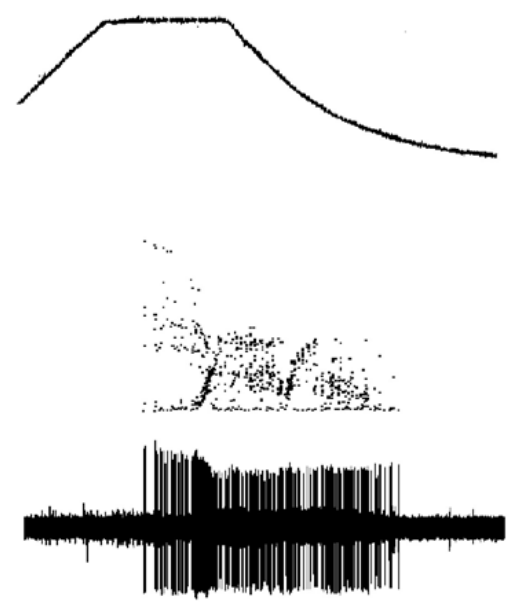

The chemical stimulus employed in this study was acetic acid, raising the possibility that the response was specifically a response to protons. Since only one concentration of chemical (acid) stimulus was used, we could not describe the stimulus-response relationship in the polymodal nociceptors. While it is possible that mechanochemical and polymodal nociceptors have slightly different thresholds in response to acid stimulation, it is interesting to note that they did not show any differences in their firing response to acid. In contrast, a study of cutaneous nociceptors in monkey (Davis et al., 1993) reported robust responses of mechanically sensitive and insensitive receptors to a noxious chemical stimulus, whereas the response of conventional polymodal receptors was significantly weaker.

The heat thresholds recorded here from mechanothermal and polymodal receptors ranged from $20^{\circ} \mathrm{C}$, though mean values were around 29 and $33^{\circ} \mathrm{C}$, respectively. This range is below that considered noxious in mammalian nociception (Koltzenburg, 1999), but can be explained by the proposition that nociceptors in fish have evolved to match habitat temperatures. Apparently greater temperature thresholds $\left(40-50^{\circ} \mathrm{C}\right)$ were reported by Sneddon (2003b). This discrepancy with the present findings is most likely due to differences in the stimulation method; Sneddon (2003b) used a thermal stimulator placed $1 \mathrm{~mm}$ above the skin in order to avoid damage. In this study, the thermal stimulator was placed in direct contact with the skin; temperatures above $43^{\circ} \mathrm{C}$ led to tissue damage and receptors became non-responsive. The upper lethal temperature for trout is around $25^{\circ} \mathrm{C}$ (Matthews and Berg, 1997). However, they will survive brief (minutes) exposure to a temperature of $35^{\circ} \mathrm{C}$ (Ineno et al., 2005). The range of these temperatures 
corresponds to the heat thresholds of nociceptors recorded here. Behavioural studies of trout in natural high temperature stream pools showed that they actively avoid temperatures above $25^{\circ} \mathrm{C}$, even at the risk of hypoxia due to the reduced oxygen content at lower temperatures (Matthews and Berg, 1997), presumably as a response to noxious heat stimulation.

A major finding of this study is the apparent absence of cold nociceptors on the head of trout. We previously reported a lack of cold receptors on the cornea (Ashley et al., 2006). If this finding is generalised over the body then it has important welfare implications, since commercial fishing practice includes live chilling and suffocation on ice. These practices are known to elicit a stress response (Roth et al., 2006) but, according to the present study, would not be nociceptive or painful. In mammals both mechanothermal (Aä) and polymodal (C-fibre) nociceptors respond robustly to noxious cold (e.g. Cain et al., 2001). Indeed, in a study of cutaneous sensory receptors in rat saphenous nerve, $100 \%$ of $A \delta$ nociceptors responded to cold, with a mean response threshold of $-4.6^{\circ} \mathrm{C}$ (Simone and Kajander, 1997). However, many species of fish can live at temperatures close to $0^{\circ} \mathrm{C}$, so that the possession of receptors with similar thresholds might be maladaptive. The evolution of nociceptors with cold sensitivity in order to detect low, potentially damaging temperatures may be linked to the transition from poikilothermy to homeothermy. Homeothermic animals need to maintain a constant body temperature and exposure to low temperatures can cause tissue damage. It would be interesting to examine a tropical teleost with a thermal range higher than trout $\left(20^{\circ} \mathrm{C}\right.$ to $\left.30^{\circ} \mathrm{C}\right)$; cold might be aversive to species that require higher temperatures.

Our attempts to induce sensitization of trout trigeminal receptor neurons were unsuccessful; receptors either retained their previous response properties or became irreversibly nonresponsive. Only one receptor out of more than 50 tested showed some evidence of sensitization, though it then became nonresponsive. In mammals, thermal, chemical and inflammatory stimuli have been shown to enhance responses of nociceptors (Lynn, 1979; Davis et al., 1993; Andrew and Greenspan, 1999). Although a role for formalin in inducing peripheral sensitization has not been demonstrated in other animals, it is used in a model for centrally mediated sensory sensitization and provides chronic noxious stimulation when applied peripherally (Abram and Yaksh, 1994). It is therefore likely to induce local responses that could lead to sensitization. We tested acetic acid since it causes prolonged adverse behavioural responses in trout, for between 3 and $6 \mathrm{~h}$ depending upon concentration (Sneddon et al., 2003a,b) and has been shown to activate primary afferent fibres in birds and frogs (Sandercock, 2004; Hamamoto and Simone, 2003). We conclude from our negative findings that the capacity for sensitization is either absent or rare for the cutaneous receptors on the head of trout, or is difficult to demonstrate in this model, possibly requiring different sensitizing stimuli. It is possible that, in cases where tissue damage leads to loss of receptor function, nociceptors adjacent to the site are sensitized. However, the in vivo recording technique used here did not allow recording from adjacent receptive fields. We suggest that sensitization may be less physiologically relevant in fish than in higher vertebrates, perhaps related to the fact that fish cutaneous receptors are more sensitive under normal conditions than those of higher vertebrates, as discussed earlier.

\section{Experimental procedures}

Experiments were conducted humanely and ethically under Home Office (UK) Guidelines. Rainbow trout (mean weight $134.11 \pm 6.65 \mathrm{~g} ; n=39$ ), obtained from a commercial supplier, were maintained in 155gallon tanks (five fish per tank maximum) with a constant flow of filtered freshwater at $15 \pm 1^{\circ} \mathrm{C}$. Fish were fed daily and kept on a 12:12 h light:dark regime. An opaque lid covered each tank and underwater shelters were provided. 
Fish were caught individually by netting, anaesthetised by immersion in benzocaine-dosed water ( $1 \mathrm{ml} / \mathrm{l}$ of $1 \mathrm{~g} / 30 \mathrm{ml}$ ethanol; Sigma-Aldrich Co., UK), weighed and then injected intraperitoneally with Saffan (0.3 ml/100 g; Schering-Plough Animal Health, Welwyn Garden City, UK). Once surgical, deep plane anaesthesia was achieved, the fish was strapped in a stainless steel cradle cushioned with polystyrene and wet paper towels. The gills were ventilated with fresh water through a custom-built mouthpiece, from an aerated circulation system held at $15 \pm 1^{\circ} \mathrm{C}$. The brain was exposed and decerebrated by removal of olfactory and optic lobes and cerebellum by suction. The neuromuscular blocker, Pavulon (pancurorium bromide, $2 \mathrm{mg} / \mathrm{ml}$; Sigma-Aldrich, UK), was injected intramuscularly $(0.08 \mathrm{ml} / 100 \mathrm{~g})$. The left trigeminal ganglion was then exposed, desheathed and covered in paraffin. Glass-insulated tungsten microelectrodes (tip diameter $10 \mu \mathrm{m}$, impedance c. $200 \mathrm{k} \Omega$; Royem Scientific Ltd., UK) were used to record extracellularly from afferent cell bodies. Signals were amplified by a NL100 head stage connected to a NL104 preamplifier (Neurolog System, Digitimer Ltd., UK) and displayed on a storage oscilloscope (5113, Tektronix Inc.). Digitised data were stored on a PC using a Micro 1401 analogue-to-digital interface and Spike 2 software (Cambridge Electronic Design, UK).

\subsection{Identification and characterization of receptors}

Stimulus-evoked activity was recorded from single cells in the trigeminal ganglion. A glass mechanical probe $(0.1 \mathrm{~mm}$ diameter) was lightly applied to the skin of the head and face in order to locate a receptive field. Once located, the receptive field diameter was measured using Vernier callipers and the mechanical threshold of the receptor determined using a custom-built mechanical stimulator. This consisted of two integrated parts - a source of stepped movement and a force measurement system. A stepper motor (Saia Burgess UBL23, RS Components Ltd., UK), controlled by pulses from a customized logic circuit board, drives the fine adjustment of a micromanipulator (MM3, Microinstruments, Oxford, UK), allowing for continuous forward or reverse motion and single shot modes, in steps of $0.03 \mathrm{~mm}$. This stepper is attached to a custom-built isometric force transducer system. Skin contact is via the end of a metal rod ( $0.5 \mathrm{~mm}$ diameter) attached to the transducer. The force-related voltage output from the transducer is displayed on an oscilloscope and via the digital CED system. The transducer was calibrated using known weights. The range of forces that could be measured was $0.0006-16.6 \mathrm{~g}$. To test for thermal sensitivity, a custom-built peltier-driven thermode with a 1-mm diameter flat contact point was placed on the receptive field and temperature raised from $15^{\circ} \mathrm{C}$ to $41^{\circ} \mathrm{C}$ at $1.25^{\circ} \mathrm{C} / \mathrm{s}$, using a thermocouple attached to the contact point and a driver feedback circuit. Once a repeatable $(3 \times)$ threshold response was established, the thermode temperature was returned to $15^{\circ} \mathrm{C}$. Cold thermal sensitivity was tested by driving the thermode temperature from $15^{\circ} \mathrm{C}$ to $-7^{\circ} \mathrm{C}$ at a rate of $1.5^{\circ} \mathrm{C} / \mathrm{s}$.

Once mechanical and thermal stimulus threshold levels had been established, further testing to record responses to stimuli above threshold was carried out. Receptors were stimulated at 1.5, 2, and 2.5 times mechanical threshold, using stimulus duration between 0.5 and $5.0 \mathrm{~s}$, and the peak firing frequency of the response was recorded. For receptors that responded to heat, peak firing frequency was also measured in response to a ramp and hold heat stimulus at temperature threshold and a separate ramp and hold stimulus at threshold plus $8^{\circ} \mathrm{C}$ ( $\mathrm{ramp}$ at $1.25^{\circ} \mathrm{C} / \mathrm{s}$; hold duration $>10 \mathrm{~s}$ after the onset of a response). The number of action potentials occurring within the first $10 \mathrm{~s}$ of the response was also recorded. To measure chemosensitivity, a single drop of $1 \%$ acetic acid $(\mathrm{pH} 2.8)$ was placed onto the skin at the centre of the receptive field. This stimulation was repeated to ensure the reaction to acid was repeatable. Peak firing frequency and the number of action potentials within the first $5 \mathrm{~s}$ of the response, were recorded. The firing response to a single drop of acid typically did not last more than $6 \mathrm{~s}$. No response was recorded from any receptor to a neutral stimulus (a drop of water) placed on the centre of the receptive field. 


\subsection{Sensitization}

A number of different approaches were used to investigate the potential for sensitization following receptor damage. These included subcutaneous injection of formalin (0.1 and $1 \%)$, topical application of acetic acid (0.5 and 1\%), subcutaneous injection of acetic acid (0.01, 0.1, 0.5 and 1\%), heat injury (application of thermode on the receptor at $45^{\circ} \mathrm{C}$ ) and cold injury (thermode at $-8^{\circ} \mathrm{C}$ and below). Following receptor characterization and threshold determination the sensitizing stimulus was administered. For subcutaneous injections, $10 \mu \mathrm{l}$ was injected $<1 \mathrm{~mm}$ from the receptive field. For topical application, a single drop was applied to the skin. For thermal injury, the thermode was applied, driven to high or low temperature at $1.25^{\circ} \mathrm{C} / \mathrm{s}$ and held for $5 \mathrm{~s}$. The response to mechanosensory stimulation was then retested immediately using the glass probe. Upon return of a receptor response, thermal and mechanical thresholds were then recorded every $20 \mathrm{~min}$, for up to $2 \mathrm{~h}$ post injection.

\subsection{Statistics}

Response thresholds, receptive field diameters, and firing responses were compared between receptor types using one-way analysis of variance (ANOVA) or an independent t-test where appropriate. When comparing receptor responses to increasing stimuli a two factor ANOVA (receptor type $x$-stimulus strength, repeated measured on last measure) was used. Planned comparisons between receptor types or between stimulus strengths within receptor types were carried out using orthogonal contrasts. Pearson correlation was used to investigate the relationship between firing response and stimulus strength. A significance level of $p<0.05$ was adopted.

\section{Acknowledgments}

We thank Jon Banks for technical assistance. This work was supported by a grant from BBSRC, UK (SS19809).

\section{References}

Abram, S.E., Yaksh, T.L., 1994. Systemic lidocaine blocks nerve injury-induced hyperalgesia and nociceptor-driven spinal sensitization in the rat. Anesthesiology 80, 383-391.

Andrew,D., Greenspan, J.D., 1999.Mechanical and heat sensitization of cutaneous nociceptors after peripheral inflammation in the rat. J. Neurophysiol. 82, 2649-2656.

Ashley, P.J., Sneddon, L.U., McCrohan, C.R., 2006. Properties of corneal receptors in a teleost fish. Neurosci. Lett. 410, 165-168.

Cain, D.M., Khasabov, S.G., Simone, D.A., 2001. Response properties of mechanoreceptors and nociceptors in mouse glabrous skin: an in vivo study. J. Neurophysiol. 85, 1561-1574.

Davis, K.D., Meyer, R.A., Campbell, J.N., 1993. Chemosensitivity and sensitization of nociceptive afferents that innervate the hairy skin of monkey. J. Neurophysiol. 69, 1071-1081.

Garell, P.C., McGillis, S.L.B, Greenspan, J.D., 1996. Mechanical response properties of nociceptors innervating feline hairy skin. J. Neurophysiol. 75, 1177-1189.

Gentle, M.J., 1989. Cutaneous sensory afferents recorded from the nervus intramandibularis of GallusGallus var Domesticus. J. Comp. Physiol., A Sens. Neural Behav. Physiol. 164, 763-774. 
Gentle, M.J., Tilston, V., McKeegan, D.E., 2001. Mechanothermal nociceptors in the scaly skin of the chicken leg. Neurosci. 106, 643-652.

Gentle, M.J., Bradbury, J.M., Wilson, S., 2003. Sensory properties of articular afferents following mycoplasma arthritis in the chicken. Brain Res. 968, 26-34.

Gonzalez, S.F., Chatziandreou, N., Nielsen, M.E., Li, W., Rogers, J., Taylor, R., Santos, Y., Cossins, A., 2007. Cutaneous immune responses in the common carp detected using transcript analysis. Mol. Immunol. 44, 1664-1679.

Hamamoto, D.T., Simone, D.A., 2003. Characterization of cutaneous primary afferent fibers excited by acetic acid in a model of nociception in frogs. J. Neurophysiol. 90, 566-577.

Ineno, T., Tsuchida, S., Kanda, M., Watabe, S., 2005. Thermal tolerance of a rainbow trout Oncorhynchus mykiss strain selected by high-temperature breeding. Fish. Sci. 71, 767-775.

Koltzenburg, M., 1999. The changing sensitivity in the life of the nociceptor. Pain Suppl. 6, S93-S102.

Leem, J.W., Willis, W.D., Chung, J.M., 1993. Cutaneous sensory receptors in the rat foot. J. Neurophysiol. 69, 1684-1699.

Lynn, B., 1979. The heat sensitization of polymodal nociceptors in the rabbit and its independence of the local blood flow. J. Physiol. 287, 493-507.

Lynn, B., 1994. The fibre composition of cutaneous nerves and the classification and response properties of cutaneous afferents, with particular reference to nociception. Pain Rev. 1, 172-183.

Matthews, K.R., Berg, N.H., 1997. Rainbow trout responses to water temperature and dissolved oxygen stress in two southern California stream pools. J. Fish Biol. 50, 50-67.

Necker, R., 2000. The somatosensory system, In: Whittow, G.C. (Ed.), Sturkie's Avian Physiology, fifth ed., pp. 57-69.

Roth, B., Slinde, E., Robb, D.H.F., 2006. Field evaluation of live chilling with CO2 on stunning Atlantic salmon (Salmo salar) and the subsequent effect on quality. Aquac. Res. 37, 799-804.

Sandercock,D.A., 2004. Putative nociceptor responses to mechanical and chemical stimulation in skeletal muscles of the chicken leg. Brain Res. Rev. 46, 155-162.

Scholz, J., Woolf, C.J., 2002. Can we conquer pain? Nat. Neurosci. Suppl. 5, 1062-10671.

Simone, D.A., Kajander, K.C., 1997. Responses of cutaneous A-fiber nociceptors to noxious cold. J. Neurophysiol. 77, 2049-2060.

Sneddon, L.U., 2002. Anatomical and electrophysiological analysis of the trigeminal nerve in a teleost fish Oncorhynchus mykiss. Neurosci. Lett. 319, 167-171.

Sneddon, L.U., 2003a. The evidence for pain in fish: the use of morphine as an analgesic. Appl. Anim. Behav. Sci. 83, 153-162.

Sneddon, L.U., 2003b. Trigeminal somatosensory innervation of the head of a teleost fish with particular reference to nociception. Brain Res. 72, 44-52. 
Sneddon, L.U., Braithwaite, V.A., Gentle, M.J., 2003a. Do fishes have nociceptors? Evidence for the evolution of a vertebrate sensory system. Proc. Roy. Soc. Lond. B 270, 1115-1121.

Sneddon, L.U., Braithwaite, V.A., Gentle, M.J., 2003b. Novel object test: examining nociception and fear in the rainbow trout. J. Pain 4, 431-440. 